\title{
Can We Predict Failure of Mitral Valve Repair?
}

\author{
Simone Gasser ${ }^{1, *}$, Maria von Stumm ${ }^{1}$, Christoph Sinning ${ }^{2}$, Ulrich Schaefer ${ }^{2}$, \\ Hermann Reichenspurner ${ }^{1}$ and Evaldas Girdauskas ${ }^{1}$ \\ 1 Department of Cardiovascular Surgery, University Heart Center Hamburg, 20251 Hamburg, Germany; \\ m.stumm@uke.de (M.v.S.); si.albers@uke.de (H.R.); e.girdauskas@uke.de (E.G.) \\ 2 Department of General and Interventional Cardiology, University Heart Center Hamburg, \\ 20251 Hamburg, Germany; c.sinning@uke.de (C.S.); schaefer.kardiologie@marienkrankenhaus.org (U.S.) \\ * Correspondence: simone.gasser@tirol-kliniken.at
}

Received: 1 March 2019; Accepted: 4 April 2019; Published: 17 April 2019

\begin{abstract}
Objective: To identify echocardiographic and surgical risk factors for failure after mitral valve repair. Methods: We identified a total of 77 consecutive patients from our institutional mitral valve surgery database who required redo mitral valve surgery due to recurrence of mitral regurgitation after primary mitral valve repair. A control group of 138 patients who had a stable echocardiographic long-term result was included based on propensity score matching. Systematic analysis of echocardiographic parameters was performed before primary surgery; after mitral valve repair and prior to redo surgery. Risk factor analysis was performed using multivariate Cox regression model. Results: Redo surgery was associated with the presence of pulmonary hypertension $\geq 50 \mathrm{mmHg}(p=0.02)$, a mean transmitral gradient $>5 \mathrm{mmHg}(p=0.001)$, left ventricular ejection fraction $\leq 45 \%(p=0.05)$ before surgery and mitral regurgitation $\geq$ moderate at time of discharge $(p=0.002)$ in the whole cohort. Patients with functional mitral valve regurgitation had a higher tendency to undergo redo surgery if preoperative left ventricular end-diastolic diameter exceeded $65 \mathrm{~mm}(p=0.043)$ and if postoperative tenting height exceeded $6 \mathrm{~mm}(p=0.018)$. Low ejection fraction was not significantly associated with the need for redo mitral valve surgery in the functional subgroup. Conclusions: Recurrent mitral regurgitation is still a valuable problem and is associated with relevant perioperative mortality. Patients with severe mitral regurgitation should undergo early mitral valve repair surgery as long as systolic pulmonary artery pressure is low, left ventricular ejection fraction is preserved, and LVEED is deceeds $65 \mathrm{~mm}$.
\end{abstract}

Keywords: mitral valve regurgitation; surgery; cardiothoracic surgery; minimally invasive mitral valve repair; redo surgery; echocardiography

\section{Introduction}

Mitral valve dysfunction (MVD) is the second most common form of heart valve disease in adults [1]. The reported annual incidence of MV disease in the industrialized nations is $\sim 3 \%$ [1]. In general, two main pathophysiological entities of MVD exist which are completely different in terms of their treatment strategies and prognosis:

Degenerative MV is the most frequent mechanism of mitral regurgitation (MR) and leads to leaflet prolapse due to elongation or rupture of chordal apparatus or, less frequently, to restrictive leaflet motion due to calcification or inflammation. An increased motion of the free edge of one or both leaflets overriding MV annular plane during the systole is defined as leaflet prolapse (Carpentier Type II dysfunction). In contrast, patients with the type IIIa dysfunction have a restricted leaflet motion due to leaflet thickening causing scarring during both diastole and systole.

Ischemic mitral incompetence leading to functional mitral regurgitation (FMR) is the most frequent mechanism of MR in developed countries [1]. It results from a global and/or regional left ventricular 
remodeling which leads to the distortion of the whole MV apparatus, including chordae, annulus, and leaflets. Ischemic MR is characterized by restrictive mitral leaflet motion during the systole due to left ventricle (LV) remodeling which occurs as a sequel of ischemic heart disease (Carpentier Type IIIb dysfunction) [1]. Patients with type I dysfunction have an extensive MV annulus dilatation and normal leaflet motion, with the free edges of the leaflets positioned 5 to $10 \mathrm{~mm}$ below the plane of the annulus due to annular dilatation [1].

Surgical treatment for severe mitral valve regurgitation is recommended for symptomatic patients with a left ventricular ejection fraction (LVEF) $>30 \%$ and asymptomatic patients if LVEF is 30-60\% and/or left ventricular end-systolicend-systolic diameter (LVESD) exceeds $40 \mathrm{~mm}$ (Class 1B Recommendations) [2]. Mitral valve repair (MVR) has become a gold standard for the correction of significant degenerative mitral regurgitation (MR) in symptomatic as well as in asymptomatic patients caused by posterior leaflet prolapse in any case or for anterior/bileaflet prolapse whenever is it is expected to be durable and associated with low morbidity and mortality, and is recommended (class I) by current guidelines [2,3]. In patients suffering from FMR (or severe secondary mitral valve regurgitation) who do not require simultaneous revascularization current guidelines are much more restrictive. Surgery is indicated in patients with an LVEF $\leq 30 \%$ who remain symptomatic despite optimal medical management and have a low operative risk [4].

Reoperation rate due to the recurrence of MV regurgitation was recently reported $5 \%$ at 5 years and between 6.2 and $13.2 \%$ at 10 years postoperatively, not taking into account underlying valve pathology. Nondegenerative valve etiology was shown to predict death after mitral valve repair [5]. However, the echocardiographic and surgical variables associated with the recurrence of mitral regurgitation/redo mitral valve surgery after MV repair remain to be clarified. Our article aims to analyze the risk factors associated with the redo MV surgery after previous MV repair with the special focus on echocardiographic and surgical variables at the time of mitral valve repair.

\section{Materials and Methods}

\subsection{Study Population}

We systematically screened our institutional MV database to identify all consecutive patients who underwent redo MV procedure after previous MV repair during the study period between March 2006 and September 2017. Inclusion criteria were degenerative or functional mitral valve regurgitation leading to MVR, and the availability of the pre- and postoperative echocardiographic images for re-review. We excluded 4 patients who had a very specific etiology of MV regurgitation, and therefore could be assigned neither to the degenerative MR nor to FMR subgroup (i.e., three patients with a cleft in the anterior mitral leaflet and one patient with systolic anterior motion (SAM) which caused MR). A total of 77 consecutive patients who underwent redo MV surgery after previous MV repair served as our study population. A total of $45(58 \%)$ patients had their initial MV surgery at our institution, while the remaining $32(42 \%)$ patients were treated externally. In the control group we considered those MVR patients who had a good functional outcome (i.e., residual MR $\leq 1$ ) for at least 5 years after primary MVR (Figure 1). Propensity score based matching (3:1) was implemented and the control group was adjusted for age, gender and underlying valve pathology (i.e., degenerative vs. functional MR). All patients agreed to process surgical and echocardiographical data for research. The paper reports on retrospective research. All data analyzed were collected as part of routine diagnosis and treatment. No ethical considerations apply. 


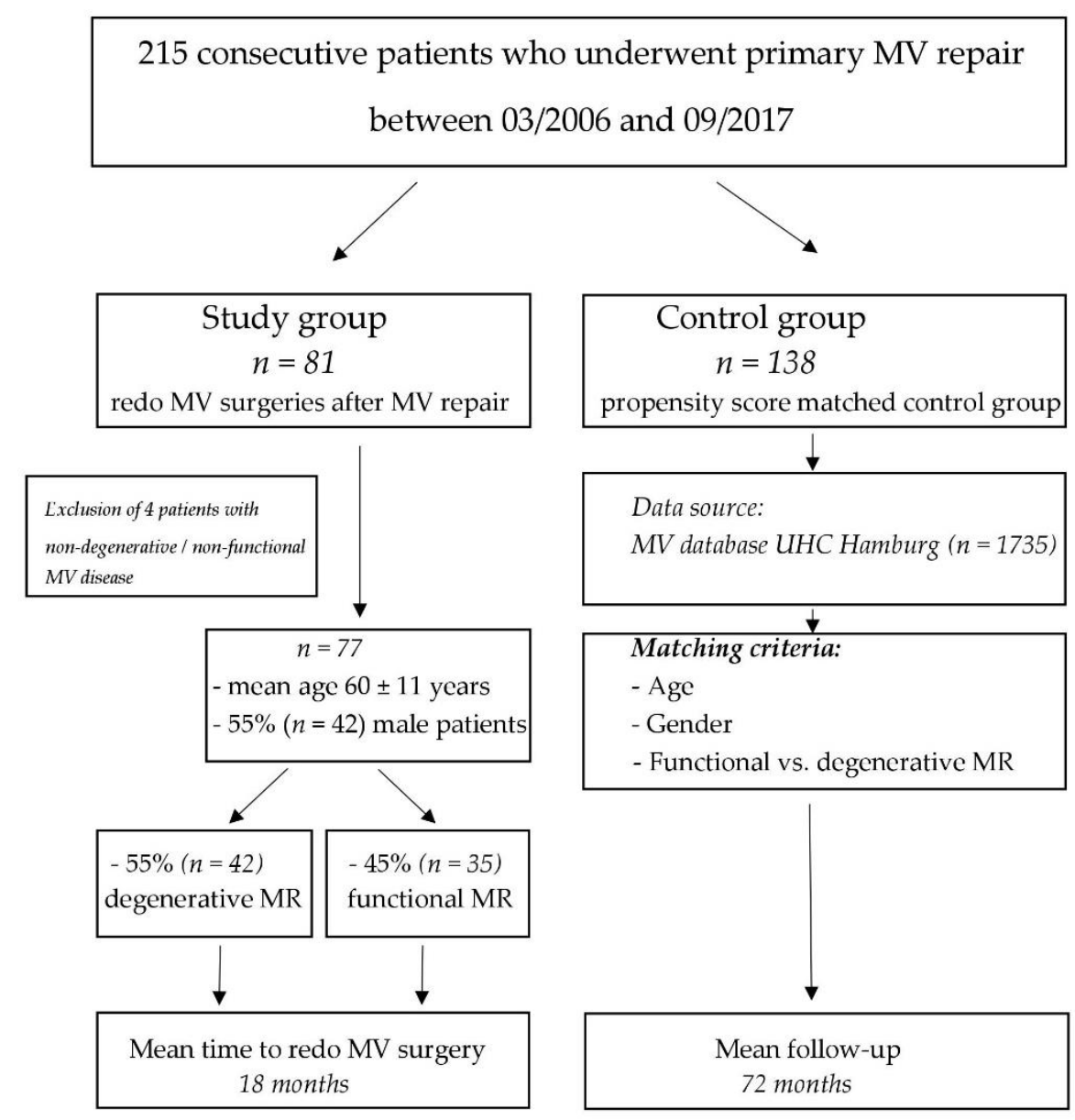

Figure 1. Patient enrollment flowchart. MV, mitral valve; UHZ, University Heart Center, Hamburg; MR, mitral regurgitation; SAM, systolic anterior movement.

\subsection{Echocardiographic Assessment}

Transthoracic echocardiography was routinely performed before initial procedure, at hospital discharge and before redo intervention. Echocardiographic assessment was performed by an attending cardiologist at institutional echolab using a standardized protocol which characterized LV/RV function, LV end-diastolic and end-systolic diameters, left atrial (LA) volume, grade of MR, MV pathology, transmitral pressure gradients, and estimated systolic pulmonary artery pressure if tricuspid regurgitation (TR) was present. Preoperative transesophageal echo was performed to specify MV pathology before redo surgery. Valve pathology was described using the Carpentier classification. Guidelines of the European Association of Cardiovascular Imaging were used for the quantification of echordiographic findings [6]. Specifically, in FMR patients, we measured tenting parameters to quantify the severity of LV remodeling: (1) PML angle (= angle between posterior mitral leaflet (PML) and mitral annular plane in the end-systole), (2) anterior mitral leaflet (AML) length in the A2 segment and (3) tenting height (i.e., the distance between the coaptation line of mitral leaflets and the annular plane) were measured in the parasternal long-axis view.

\subsection{Operative Technique}

Surgery was performed via median sternotomy or right anterolateral mini-thoracotomy, depending on patients' comorbidities/surgical risk and the concomitant procedures required. In degenerative mitral valve disease, leaflet prolapse was addressed first [7] using a leaflet resection or artificial neochordae implantation techniques. In Barlow's disease bileaflet prolapse was corrected, followed by subsequent implantation of a large annuloplasty ring [8]. Circumferential ring annuloplasty 
was generally used in the degenerative mitral regurgitation (DMR) and ring sizing was performed according to the surface area of AML and total mitral valve orifice area. Type I MR was usually addressed by a downsized annuloplasty ring only (11). In Type IIIb MR a specifically designed annuloplasty ring (e.g., Carpentier-Edwards-McCarthy-Adams IMR ETLOGIX-Ring, Edwards Lifesciences, Irvine, CA, USA) with a reduced a-p diameter was used. Matress U-shaped sutures were used in the posterior mitral annulus to reduce the risk of tear of annuloplasty ring. Adjunct subannular techniques in Type IIIb MR were introduced more recently to restore optimal leaflet coaptation plane and to reduce the tenting area [9]. Papillary muscle repositioning is now routinely used for this purpose which has been recently published by our group [9]. Intraoperative transesophageal echocardiographic study was routinely performed to assess MV competence after discontinuation from cardiopulmonary bypass (CPB). For the present study, the definition of a minimally invasive operation was limited to MV surgery performed through a right minithoracotomy.

\subsection{Statistical Analysis}

SPSS 24 (IBM, Armonk, NY, USA) was used for all statistical analyzes. The data are presented as mean \pm standard deviation for continuous variables and as percentages for categorical variables, unless otherwise specified. Propensity score matching was performed between study and control group using 3 adjusting variables: age, gender, and etiology of MVD (i.e., degenerative vs. functional MR). Univariate analysis was performed using $t$-test for group the numeric variables and chi-squared test/Fisher exact test for the nominal variables. Cox proportional hazards regression was performed to identify risk factors predisposing patients to mitral valve redo surgery. All variables from univariate analysis with $p<0.1$ were included in the multivariate model. $p$-values $<0.05$ were considered statistically significant.

\section{Results}

\subsection{Baseline Characteristics}

A total cohort of 215 patients was analyzed (i.e., after inclusion of the control group based on propensity score matching). The cohort consisted of degenerative MR subgroup ( $n=147 ; 68 \%$ ) and functional MR subgroup $(n=68 ; 32 \%)$. Mean age was $61 \pm 11$ years and 131 patients $(61 \%)$ were male. Preoperative variables in the whole study cohort and in both study subgroups are presented in Table 1. The mean follow-up period was $72 \pm 11$ months. Redo mitral surgery was performed at a median interval of 18.5 months after previous mitral valve repair and resulted in an in-hospital mortality of $8.5 \%$ compared to $0.14 \%$ after primary surgery. The median interval was predominantly due to early failures in the type IIIb FMR patients' subgroup, as opposed to the late failures in our DMR cohort. Early redo surgery war required in eight DMR patients due to endocarditis and five DMR patients referred for early redo MV surgery after primary MV repair surgery in an external institution. Increased mortality rate of $8.5 \%$ in the entire redo cohort was predominantly due to early deaths in the FMR cohort. Patients in the FMR cohort were significantly older, had much higher surgical risk scores and severely reduced systolic LV function. Contrarily, in-hospital mortality in the DMR cohort was low $(1.8 \%)$ (Table 1$)$. 
Table 1. Preoperative and operative characteristics and $p$-values for matching parameters. Echocardiographical data was collected before primary surgery and operative characteristics describe surgical strategy for primary repair.

\begin{tabular}{|c|c|c|c|c|}
\hline & $\begin{array}{l}\text { Whole Cohort } \\
\quad(n=215)\end{array}$ & $\begin{array}{l}\text { Redo Group } \\
\quad(n=77)\end{array}$ & $\begin{array}{l}\text { Control Group } \\
\quad(n=138)\end{array}$ & $p$-Value for Matching \\
\hline Age, $y$ & $61 \pm 11$ & $60 \pm 11$ & $61 \pm 11$ & 0.58 \\
\hline Male & $131(61 \%)$ & $42(55 \%)$ & $89(64 \%)$ & 0.85 \\
\hline \multicolumn{5}{|c|}{ Preoperative echocardiographic assessment } \\
\hline $\begin{array}{c}\text { Ejection fraction, \% } \\
\text { preserved (m 52-72; f 54-74) }\end{array}$ & 151 (71\%) & 49 (64\%) & $102(76 \%)$ & 0.07 \\
\hline mild dysfunction (m 41-51; f 41-53) & $30(14 \%)$ & $10(13 \%)$ & $20(14 \%)$ & 0.64 \\
\hline moderate dysfunction (m \& f 30-40) & $20(9 \%)$ & $11(14 \%)$ & $9(6 \%)$ & 0.02 \\
\hline severe dysfunction $(\mathrm{m} \& \mathrm{f}<30)$ & $14(6 \%)$ & $7(9 \%)$ & $7(4 \%)$ & 0.09 \\
\hline \multicolumn{5}{|l|}{ Etiology } \\
\hline degenerative & $147(68 \%)$ & $42(55 \%)$ & $105(76 \%)$ & 0.3 \\
\hline -Type II & $140(65 \%)$ & $38(50 \%)$ & $102(74 \%)$ & \\
\hline -Type IIIa & $7(3 \%)$ & $4(5 \%)$ & $3(2 \%)$ & \\
\hline functional & $68(32 \%)$ & $35(45 \%)$ & $33(24 \%)$ & 0.3 \\
\hline -Type I & $28(13 \%)$ & $15(19 \%)$ & $13(10 \%)$ & \\
\hline -Type IIIb & $40(19 \%)$ & $20(26 \%)$ & $20(14 \%)$ & \\
\hline Leaflet prolapse & $140(66 \%)$ & $38(49 \%)$ & $102(74 \%)$ & $<0.01$ \\
\hline none & $28(13 \%)$ & $15(20 \%)$ & $13(9 \%)$ & $<0.01$ \\
\hline AML & $21(10 \%)$ & $9(12 \%)$ & $12(9 \%)$ & 0.36 \\
\hline PML & $99(47 \%)$ & $20(26 \%)$ & $79(57 \%)$ & $<0.01$ \\
\hline bileaflet & $20(9 \%)$ & $4(5 \%)$ & $16(12 \%)$ & 0.17 \\
\hline Leaflet restriction & $47(22 \%)$ & $24(31 \%)$ & $23(17 \%)$ & 0.02 \\
\hline \multicolumn{5}{|c|}{ Operative Characteristics } \\
\hline Cardiopulmonary bypass time, $\min$ & $163(51 ; 412)$ & $160(51 ; 412)$ & $165(51 ; 314)$ & 0.9 \\
\hline Isolated Mitral Valve Repair & $165(77 \%)$ & $40(52 \%)$ & $125(90.6 \%)$ & $<0.01$ \\
\hline Minimally invasive approach & $133(62 \%)$ & $16(21 \%)$ & $117(85 \%)$ & $<0.01$ \\
\hline Concomitant Procedures & $50(23 \%)$ & $37(48 \%)$ & $13(9 \%)$ & \\
\hline CABG & $20(7 \%)$ & $10(13 \%)$ & $10(7 \%)$ & \\
\hline AVR & $13(5 \%)$ & $12(15 \%)$ & $1(0.7 \%)$ & \\
\hline $\mathrm{CABG}+\mathrm{AVR}$ & $1(0.4 \%)$ & - & $1(0.7 \%)$ & \\
\hline Tricuspid Valve Surgery & $9(4 \%)$ & $8(10 \%)$ & $1(0.7 \%)$ & $<0.01$ \\
\hline CABG + Tricuspid Valve Surgery & $2(0.7 \%)$ & $2(3 \%)$ & - & \\
\hline AVR + Tricuspid Valve Surgery & $1(0.4 \%)$ & $1(1 \%)$ & - & \\
\hline Ablation Procedure & $3(1.4 \%)$ & $3(4 \%)$ & - & \\
\hline Septal Myectomy & $1(0.4 \%)$ & $1(1 \%)$ & - & \\
\hline \multicolumn{5}{|l|}{ Size of mitral annuloplasty } \\
\hline $28-36 \mathrm{~mm}$ & $205(96 \%)$ & $72(93 \%)$ & $133(97 \%)$ & 0.98 \\
\hline \multicolumn{5}{|l|}{ Type of leaflet repair } \\
\hline Neochordae & $36(17 \%)$ & $14(18 \%)$ & $22(16 \%)$ & 0.91 \\
\hline Resection & $58(27 \%)$ & $7(9 \%)$ & $51(37 \%)$ & 0.008 \\
\hline Neochordae + Resection & $17(8 \%)$ & $4(5 \%)$ & $13(9 \%)$ & 0.83 \\
\hline
\end{tabular}

AML, anterior mitral leaflet; PML, posterior mitral leaflet; CABG, coronary artery bypass graft; AVR, aortic valve replacement.

\subsection{Surgical Strategies}

A minimally invasive approach via right anterolateral mini-thoracotomy was used in 133 patients (62\%). An annuloplasty ring between 28 and $34 \mathrm{~mm}$ diameter was used in the majority of patients (i.e., $n=181(84 \%))$. The most frequently used annuloplasty ring type was Carpentier-Edwards Physio-II (Edwards Lifesciences, Irvine, CA, USA) in 166 patients (77\%). A total of $50(23 \%)$ patients underwent concomitant procedures, 13 of them with degenerative mitral valve disease. In the degenerative MR subgroup $(n=147), 53(36 \%)$ patients undewent polytetrafluoroethylene (PTFE) neochordae 
implantation, while resection strategy was used in $75(51 \%)$ patients. Univariate analysis showed a significant difference in strategy of treatment of prolapse for recurrence rate of MR (i.e., neochoardea implanation vs. resection; $p=0.004$ ) which could not be confirmed in our multivariate model. Ring annuloplasty was shown to be necessary for success of MVR, especially for patients with degenerative mitral valve disease only (hazard ratio (HR) 4.1, $p=0.04$ ). Choice of ring size made no statistically significant difference in FMR patients. In FMR patients $(n=67), 29 \%$ of repairs were performed through minimally invasive thoracotomy. Thirteen patients (19\%) required concomitant coronary artery bypass graft (CABG) and $7(10 \%)$ additional tricuspid valve repair. Subannular techniques were not used in the primary MV repair procedures.

\subsection{Echocardiographic Parameters Associated with the Redo MV Surgery in the Whole Study Cohort}

Multivariate Cox regression analysis revealed a statistically significant association between the redo MV surgery and preoperative systolic pulmonary artery pressure $\geq 50 \mathrm{mmHg}$ ( $\mathrm{HR} 2.3$; $p=0.02)$, preoperative mean transmitral pressure gradient $>5 \mathrm{mmHg}(\mathrm{HR} 3.3, p=0.001)$, and reduced LVEF $(\leq 45 \%)$ before surgery (HR 2.1; $p=0.05$ ) regardless underlying valve pathology. AML length, left ventricular end-diastolic diameter (LVEDD), LVESD, and tricuspid regurgitation $\geq$ moderate demonstrated no significant association with the redo MV surgery in the multivariate cox regression analysis. All of these echocardiographical parameters were collected prior to initial mitral valve repair.

Mitral regurgitation $\geq$ moderate at the time of hospital discharge after MVR was significantly associated with the need of MV reintervention during the follow-up (HR 5.8; $p=0.002$ ). The data of cox regression analysis for the whole cohort is summarized in Table 2.

Table 2. Echocardiographical risk factors for redo mitral valve (MV) surgery in the whole study cohort (Cox regression model). Parameters were collected prior to initial mitral valve repair.

\begin{tabular}{ccccc}
\hline Multivariate Analysis & \multicolumn{4}{c}{ Entire Study Cohort $(n=215)$} \\
\hline Variable & Redo Group & Control Group & HR & $p$-Value \\
\hline Systolic PAP $\geq 50 \mathrm{mmHg}$ & $16(21 \%)$ & $13(9 \%)$ & 2.3 & 0.02 \\
TR $\geq$ moderate & $13(17 \%)$ & $14(10 \%)$ & 1.04 & 0.87 \\
AML length $(\mathrm{mm})$ & $30 \pm 8$ & $30 \pm 7$ & 0.5 & 0.29 \\
Pmean $>5 \mathrm{mmHg}$ & $7(9 \%)$ & $2(1 \%)$ & 3.3 & 0.001 \\
LVEF $\leq 45 \%$ & $15(19 \%)$ & $14(10 \%)$ & 2.1 & 0.05 \\
LVEDD $(\mathrm{mm})$ & $62 \pm 11$ & $61 \pm 9$ & 2.3 & 0.78 \\
MR at discharge $\geq$ moderate & $17(22 \%)$ & $7(5 \%)$ & 5.8 & 0.002 \\
\hline
\end{tabular}

$\mathrm{MV}$, mitral valve; PAP, pulmonary artery pressure; TR, tricuspid regurgitation; AML, anterior mitral leaflet; Pmean, mean pressure gradient; LVEF, left ventricular ejection fraction; LVEDD, left ventricular enddiastolic diameter; MR, mitral regurgitation; HR, hazard ratio.

\subsection{Predictors for Redo MV Surgery in the Degenerative MR Subgroup}

Univariate analysis revealed a trend towards increased risk of redo MV surgery in DMR patients with non-PML prolapse. However, there was no significant association between this variable and redo MV surgery in the multivariable Cox regression analysis. None of the pre- or postoperative echocardiographic parameters showed a significant association with the redo MV surgery, including TR $\geq$ moderate, type of leaflet disease or LVEDD, and LVESD diameters systole or diastole, prior, and after MV repair in degenerative patients. For further details see Table 3. 
Table 3. Risk factors for redo MV surgery in the degenerative mitral regurgitation (DMR) subgroup (Cox regression model). Parameters were collected prior to initial mitral valve repair.

\begin{tabular}{ccccc}
\hline Multivariate Analysis & \multicolumn{4}{c}{ Degenerative Mitral Valve Disease $(\boldsymbol{n}=\mathbf{1 4 7})$} \\
\hline Variable & Redo Group & Control Group & HR & $\boldsymbol{p}$-Value \\
\hline Bileaflet_prolapse & $3(8.3 \%)$ & $17(15 \%)$ & 0.57 & 0.7 \\
Non-PML prolapse & $11(31 \%)$ & $30(27 \%)$ & 0.23 & 0.16 \\
sPAP $\geq 50$ mmHg & $6(17 \%)$ & $9(8 \%)$ & 1.63 & 0.43 \\
LVEF $\leq 45 \%$ & $2(5.5 \%)$ & $3(2.7 \%)$ & 0.52 & 0.65 \\
MR at discharge $\geq$ moderate & $7(19.4 \%)$ & $2(1.8 \%)$ & 14.5 & 0.006 \\
\hline
\end{tabular}

$\mathrm{MV}$, mitral valve; DMR, degenerative mitral regurgitation; PML, posterior mitral leaflet; PAP, pulmonary artery pressure; LVEF, left ventricular ejection fraction.

\subsection{Echocardiographic Parameters Associated with Redo MV Surgery in the FMR Subgroup}

Reduced LV ejection fraction $(\leq 45 \%)$ pre- or postsurgery was not associated with an increased risk of redo MV surgery in the FMR subgroup (Table 4). Furthermore, we were unable to demonstrate a significant association between preoperative tenting parameters (i.e., PML-angle, tenting height) and the redo MV surgery in the FMR cohort. The length of AML as well as elevated systolic pulmonary artery pressure (sPAP) in the preoperative echocardiography had similarly no significant association with MV reinterventions (Table 4). Only the preoperative LV end-diastolic diameter (LVEDD) $\geq 65 \mathrm{~mm}$ (HR 3.67; $p=0.043$ ) showed an increased risk for redo surgery.

Furthermore, Cox regression analysis revealed a significant impact of postrepair tenting height on the risk of redo MV surgery. Post-MVR tenting height of $\geq 6 \mathrm{~mm}$ (HR 2.3; $p=0.018$ ) had a negative impact on the risk of mitral valve redo surgery in our FMR cohort.

Table 4. Echocardiographical risk factors prior to initial mitral valve repair for redo MV surgery in the functional mitral regurgitation (FMR) subgroup (Cox regression model).

\begin{tabular}{ccccc}
\hline Multivariate Analysis & \multicolumn{3}{c}{ Functional Mitral Valve Disease $(\boldsymbol{n}=\mathbf{6 8})$} \\
\hline Variable & Redo Group & Control Group & HR & $p$-Value \\
\hline LVEDD $\geq 65 \mathrm{~mm}$ & $13(36 \%)$ & $4(12.5 \%)$ & 3.67 & 0.043 \\
PML angle $\left(^{\circ}\right)$ & $35 \pm 11$ & $32 \pm 12$ & 0.2 & 0.49 \\
AML length $(\mathrm{mm})$ & $28 \pm 5$ & $27 \pm 7$ & 0.01 & 0.48 \\
Tenting height $\geq 8 \mathrm{~mm}$ & $13(36 \%)$ & $6(19 \%)$ & 1.8 & 0.41 \\
LVEF $\leq 45 \%$ & $13(36 \%)$ & $11(34 \%)$ & 1.2 & 0.46 \\
Parameters before discharge & & & & \\
PML angle $\left(^{\circ}\right)$ & $40 \pm 12$ & $40 \pm 10$ & 0.9 & 0.1 \\
Tenting height $\geq 6 \mathrm{~mm}$ & $11(31 \%)$ & $3(9 \%)$ & 2.3 & 0.018 \\
\hline
\end{tabular}

MV, mitral valve; FMR, functional mitral regurgitation; LVEDD, left ventricular end-diastolic diameter; $\mathrm{PML}$, posterior mitral leaflet; $\mathrm{AML}$, anterior mitral leaflet; $\mathrm{LVEF}$, left ventricular ejection fraction.

\section{Discussion}

The prevalence of reoperation due to recurrent MV regurgitation was recently reported 5\% at 5 years and $9.5 \%$ at 10 years postoperatively. Nondegenerative valve etiology was shown to predict death after mitral valve repair [5]. We strongly consider redo MV surgery for failed repair in the FMR entity, especially in the setting of an obvious clinical deterioration and if re-repair seems possible, although clinical guidelines for this approach are very restrictive. However, the echocardiographic and surgical variables associated with the recurrence of mitral regurgitation/redo mitral valve surgery are still an object of controversial debate.

The recurrence of MR does not only increase the long-term mortality but significantly worsens quality of life [10]. MR recurrence in DMR patients with an isolated anterior leaflet prolapse or bileaflet prolapse is of major clinical interest and warrants detailed comparison of surgical techniques and echocardiographic parameters which may lead to repair failure. 
The most important findings of our current study are (1) preoperative echocardiographic parameters can help to predict success of mitral valve repair. In particular, our study revealed systolic pulmonary artery pressure $\geq 50 \mathrm{mmHg}$, a mean transmitral pressure gradient $>5 \mathrm{mmHg}$ and reduced LVEF $\leq 45 \%$ as significant parameters associated with recurrence of MR leading to redo surgery in the whole population. (2) Left ventricular function had no impact on success of mitral valve repair in FMR, but left ventricular end-diastolic diameter as well as postoperative tenting height did. We imply that patients with severe MR should be admitted to surgery as early as possible and that repair is also feasible in FMR patients with poor ventricular function.

\subsection{Whole Study Population}

Our study confirms that reduced ejection fraction is detrimental for recurrent MR in the whole study population that underwent MVR and for survival of DMR patients undergoing MVR [11-15]. Elevated systolic pulmonary artery pressure has also been shown to have a negative impact on survival (all MV etiologies) as well as on recurrence of MR for DMR patients [11,12,15-17]. We could confirm that finding in our study for the whole study cohort regardless etiology of MVR. The possible pathophysiological explanation for this finding might be referral to surgery in an advanced stage of MV disease with progressed left ventricular and left atrial remodeling with complex changes not only effecting systolic but also diastolic function. SPAP improves early after surgery, but residual pulmonary hypertension was observed in all patients with pulmonary artery pressure $\geq 40 \mathrm{mmHg}$ and predicted operative mortality, long-term mortality, and morbidity in Ghoreishi et al.'s study [17].

Another finding of our study was higher reoperation rates for patients with preoperatively elevated systolic transmitral valve gradient (i.e., mean transmitral gradient $\geq 5 \mathrm{mmHg}$ ). This finding is consistent with Coutinho et al.'s study on failures of MVR for degenerative mitral valve disease and might be explained by extensive MV leaflet degeneration which leads to progressive mitral valve stenosis/regurgitation after MVR [18].

\subsection{Degenerative Mitral Regurgitation (DMR) Subgroup}

Recently published data reported a 5.9\% reoperation rate during 20 years of follow up in DMR patients $[12,13,19,20]$. The need for redo surgery was associated with an increased age, reduced LVEF, isolated AML prolapse, lack of annuloplasty, long CPB time, elevated SPAP, and evidence of myxomatous changes in the MV, as well as preoperative history of atrial fibrillation (AF) $[12,13,19,20]$. All of our DMR patients received ring annuloplasty. All remaining variables were not significantly associated with need for redo surgery in our DMR subgroup. We did not examine the impact of AF on redo surgery in our population. Localization of mitral valve prolapse had no impact on outcome in our study cohort. This might be explained by the learning curve of mitral valve surgeons over the last decades and their present experience in treating any mitral valve pathology. The studies reporting isolated AML prolapse and lack of annuloplasty as independent predictors of redo mitral valve surgery represent a rather historical cohort (24). These reports may represent the surgical evolution and technical improvements in MV repair techniques, while the results of posterior leaflet prolapse repair were initially better than those of repaired nonposterior leaflet lesions [21]. Our study supports the recent findings that bileaflet and anterior leaflet prolapse repair can be performed with similar long-term results as compared to the posterior leaflet prolapse in experienced centers [18].

\subsection{Functional Mitral Regurgitation Subgroup}

Preoperatively enlarged LVEDD $\geq 65 \mathrm{~mm}$ was associated with an increased reoperation rate in the FMR subgroup.

Increased tenting height has been previously reported as a determinant of FMR recurrence after an isolated annuloplasty [10], and was also found to be decisive for outcome in our FMR cohort (i.e., tenting height $\geq 6 \mathrm{~mm}$ at discharge transthoracic echocardiography). The deleterious effect of increasing LVEDD diameter has been similarly reported by the previous studies [10,22-24], and is 
supported by our subgroup analysis for FMR patients (LVEDD $\geq 65 \mathrm{~mm}$ ). Increased PML-angle was reported to be a predictor of FMR recurrence as well as basal LV aneurysm/dyskinesia, which could not be confirmed [24]. The possible explanation for that is our limited sample size and potential heterogeneity of FMR cohort including ischemic, dilated, and valvular cardiomyopathies, and that basal LV aneurysms/dyskinesia were not captured by our MV database.

There is sufficient amount of evidence in the literature showing that an isolated annuloplasty leaves uncorrected residual mitral leaflet tethering and therefore results in high MR recurrence rates in type IIIb FMR disease [25]. MR recurrence rates of 28 to $58 \%$ have been reported during the first $1-2$ postoperative years after an isolated annuloplasty in type IIIb FMR [26-28]. Such dismal results of an isolated annuloplasty in type IIIb FMR disease underscore the need for additional subannular maneuvers to address the distorted LV geometry in those patients. Given the fact that mitral leaflet tethering in type IIIb FMR results from progressively increasing distance between the tips of papillary muscles and the mitral annular plane, an isolated annuloplasty that addresses 'only' mitral valve annular plane is unable to pathophysiologically correct the underlying leaflet tethering [26]. Therefore, papillary muscle repositioning (Supplementary video S1) added to the standard ring annuloplasty procedure, has a potential to reduce late recurrence rate of type IIIb MR and thereby eliminate the reoperation risk [29-32].

\section{Study Limitations}

Our study has some important limitations. Although propensity score matching was intended to overcome the limitations of this retrospective analysis, there may still be some important differences between the study groups. The inclusion of patients with different MV pathologies in the analysis (i.e., degenerative and functional MR) may potentially weaken the findings of our study. However, the sample size in both MR subgroups was limited and the combination of both resulted in a reasonable size of the total study cohort. Experience in mitral valve repair possibly varied between surgeons performing primary mitral valve repair. Including various surgeons from different institutions is a limitation of our study. Another major limitation is that our study endpoint of redo MV surgery does not necessarily identifies all patients with the recurrent relevant MR. Furthermore, MR was not quantified by PISA/ERO and there was only a small number of 3D echocardiographies. We acknowledge the fact that our study endpoint of redo MV surgery potentially misses those patients who develop significant MR after MV repair, but are never referred for redo surgery. Potential reasons for nonreferring these patients for redo surgery may include (1) rejection due to prohibitive surgical risk, (2) patients refuse redo surgery themselves, (3) death before diagnosis, or (4) physicians/cardiologists are reluctant to refer the patient for redo surgery despite relevant MR. Furthermore some patients may have been transferred to other institutions for redo surgery and therefore not captured by our database. Given these limitations, a systematic echocardiographic follow-up of all patients who underwent previous MV repair is obligatory to obtain more sophisticated data on MR recurrence and was not carried out at our institution over the period of the last 11 years.

In addition, an observational study over a long time period may be potentially biased by continuous improvement in the surgical techniques over time and improving skills of the surgical team.

\section{Conclusions}

Although rare, recurrent mitral valve regurgitation is still a significant problem and is associated with relevant perioperative mortality. Our study supports the fact that patients with severe MR should be admitted to early surgery as long as systolic pulmonary artery pressure is low and left ventricular ejection fraction is preserved.

Supplementary Materials: The following are available online at http://www.mdpi.com/2077-0383/8/4/526/s1, Video S1: Video 1 is an operative video showing papillary muscle repositioning, a novel technique to reduce incidence of failure after mitral valve repair in FMR patients with Type IIIlb dysfunction. 
Author Contributions: Conceptualization, S.G. and E.G.; Data Curation, S.G. and C.S.; Formal Analysis, S.G., C.S. and E.G.; Investigation, S.G.; Methodology, S.G., C.S., and E.G.; Project Administration, S.G. and E.G.; Resources, S.G., C.S., and H.R.; Supervision, H.R. and E.G.; Validation, M.v.S., H.R., and E.G.; Visualization, S.G.; Writing-Original Draft, S.G.; Writing-Review \& Editing, M.v.S., U.S., and E.G.

Conflicts of Interest: The authors declare no conflicts of interest.

$\begin{array}{ll}\text { Abbreviations } \\ \text { MVR } & \text { mitral valve repair } \\ \text { MVD } & \text { mitral valve disease } \\ \text { MR } & \text { mitral regurgitation } \\ \text { LV } & \text { left ventricle } \\ \text { RV } & \text { right ventricle } \\ \text { LA } & \text { left atrium } \\ \text { FMR } & \text { functional mitral regurgitation } \\ \text { DMR } & \text { degenerative mitral regurgitation } \\ \text { TR } & \text { tricuspid regurgitation } \\ \text { LVEDD } & \text { left ventricular end-diastolic diameter } \\ \text { LVESD } & \text { left ventricular end-systolic diameter } \\ \text { AP } & \text { anteroposterior diameter of mitral annulus } \\ \text { AML } & \text { anterior mitral leaflet } \\ \text { PML } & \text { posterior mitral leaflet } \\ \text { EF } & \text { ejection fraction } \\ \text { sPAP } & \text { systolic pulmonary artery pressure } \\ \text { CBP } & \text { Cardiopulmonary Bypass } \\ \text { PTFE } & \text { polytetrafluoroethylene } \\ \text { AVR } & \text { Aortic valve replacement }\end{array}$

\section{References}

1. Madesis, A.; Tsakiridis, K.; Zarogoulidis, P.; Katsikogiannis, N.; Machairiotis, N.; Kougioumtzi, I.; Kesisis, G.; Tsiouda, T.; Beleveslis, T.; Koletas, A.; et al. Review of mitral valve insufficiency: Repair or replacement. J. Thorac. Dis. 2014, 6, 39-51.

2. Nishimura, R.A.; Otto, C.M.; Bonow, R.O.; Carabello, B.A.; Erwin, J.P., 3rd; Fleisher, L.A.; Jneid, H.; Mack, M.J.; McLeod, C.J.; O'Gara, P.T.; et al. 2017 AHA/ACC focused update of the 2014 AHA/ACC guideline for the management of patients with valvular heart disease: A report of the american college of cardiology/american heart association task force on clinical practice guidelines. J. Am. Coll. Cardiol. 2017, 70, 252-289. [CrossRef]

3. Coutinho, G.F.; Antunes, M.J. Mitral valve repair for degenerative mitral valve disease: Surgical approach, patient selection and long-term outcomes. Heart 2017, 103, 1663-1669. [CrossRef] [PubMed]

4. EACTS. ESC/EACTS guidelines for the management of valvular heart disease published today. Available online: https://academic.oup.com/eurheartj/article/38/36/2739/4095039\#114546712 (accessed on 20 April 2018).

5. Tatum, J.M.; Bowdish, M.E.; Mack, W.J.; Quinn, A.M.; Cohen, R.G.; Hackmann, A.E.; Barr, M.L.; Starnes, V.A. Outcomes after mitral valve repair: A single-center 16-year experience. J. Thorac. Cardiovasc. Surg. 2017, 154, 822-830. [CrossRef]

6. Popovic, Z.B.; Sato, K.; Desai, M.Y. Is universal grading of diastolic function by echocardiography feasible? Cardiovasc. Diagn. Ther. 2018, 8, 18-28. [CrossRef] [PubMed]

7. Gillinov, A.M.; Cosgrove, D.M. Mitral valve repair for degenerative disease. J. Heart Valve Dis. 2002, 11, 15-20.

8. Adams, D.H.; Anyanwu, A.C.; Rahmanian, P.B.; Abascal, V.; Salzberg, S.P.; Filsoufi, F. Large annuloplasty rings facilitate mitral valve repair in barlow's disease. Ann. Thorac. Surg. 2006, 82, 2096-2101. [CrossRef] [PubMed]

9. Carpentier, A.; Adams, D.H.; Filsoufi, F. Carpentier's Reconstructive Valve Surgery: From Valve Analysis to Valve Reconstruction; Saunders/Elsevier: Maryland Heights, Missouri, MO, USA, 2010. 
10. Ciarka, A.; Braun, J.; Delgado, V.; Versteegh, M.; Boersma, E.; Klautz, R.; Dion, R.; Bax, J.J.; Van de Veire, N. Predictors of mitral regurgitation recurrence in patients with heart failure undergoing mitral valve annuloplasty. Am. J. Cardiol. 2010, 106, 395-401. [CrossRef] [PubMed]

11. Castillo-Sang, M.; Guthrie, T.J.; Moon, M.R.; Lawton, J.S.; Maniar, H.S.; Damiano, R.J., Jr.; Silvestry, S.C. Outcomes of repeat mitral valve surgery in patients with pulmonary hypertension. Innovations (Phila) 2015, 10, 120-124. [PubMed]

12. Murashita, T.; Okada, Y.; Kanemitsu, H.; Fukunaga, N.; Konishi, Y.; Nakamura, K.; Koyama, T. The impact of preoperative and postoperative pulmonary hypertension on long-term surgical outcome after mitral valve repair for degenerative mitral regurgitation. Ann. Thorac. Cardiovasc. Surg. 2015, 21, 53-58. [CrossRef] [PubMed]

13. Chenot, F.; Montant, P.; Vancraeynest, D.; Pasquet, A.; Gerber, B.; Noirhomme, P.H.; El Khoury, G.; Vanoverschelde, J.L. Long-term clinical outcome of mitral valve repair in asymptomatic severe mitral regurgitation. Eur. J. Cardiothorac. Surg. 2009, 36, 539-545. [CrossRef] [PubMed]

14. Wang, J.; Han, J.; Li, Y.; Xu, C.; Jiao, Y.; Yang, B.; Meng, X.; Bolling, S.F. Preoperative risk factors of medium-term mitral valve repair outcome. Interact. Cardiovasc. Thorac. Surg. 2014, 19, 946-954. [CrossRef] [PubMed]

15. Zhuo, D.X.; Bilchick, K.C.; Mazimba, S. Preoperative invasive hemodynamic determinants of survival among patients undergoing aortic or mitral valve surgery. J. Cardiothorac. Vasc. Anesth. 2018, 32, 1273-1280. [CrossRef] [PubMed]

16. Pardi, M.M.; Pomerantzeff, P.M.A.; Sampaio, R.O.; Abduch, M.C.; Brandao, C.M.A.; Mathias, W., Jr.; Grinberg, M.; Tarasoutchi, F.; Vieira, M.L.C. Relation of mitral valve morphology to surgical repair results in patients with mitral valve prolapse: A three-dimensional transesophageal echocardiography study. Echocardiography 2018, 35, 1342-1350. [CrossRef] [PubMed]

17. Ghoreishi, M.; Evans, C.F.; DeFilippi, C.R.; Hobbs, G.; Young, C.A.; Griffith, B.P.; Gammie, J.S. Pulmonary hypertension adversely affects short- and long-term survival after mitral valve operation for mitral regurgitation: Implications for timing of surgery. J. Thorac. Cardiovasc. Surg. 2011, 142, 1439-1452. [CrossRef] [PubMed]

18. Coutinho, G.F.; Correia, P.M.; Branco, C.; Antunes, M.J. Long-term results of mitral valve surgery for degenerative anterior leaflet or bileaflet prolapse: Analysis of negative factors for repair, early and late failures, and survival. Eur. J. Cardiothorac. Surg. 2016, 50, 66-74. [CrossRef]

19. David, T.E.; Armstrong, S.; McCrindle, B.W.; Manlhiot, C. Late outcomes of mitral valve repair for mitral regurgitation due to degenerative disease. Circulation 2013, 127, 1485-1492. [CrossRef]

20. Shimokawa, T.; Kasegawa, H.; Katayama, Y.; Matsuyama, S.; Manabe, S.; Tabata, M.; Fukui, T.; Takanashi, S. Mechanisms of recurrent regurgitation after valve repair for prolapsed mitral valve disease. Ann. Thorac. Surg. 2011, 91, 1433-1439. [CrossRef]

21. Suri, R.M.; Clavel, M.A.; Schaff, H.V.; Michelena, H.I.; Huebner, M.; Nishimura, R.A.; Enriquez-Sarano, M. Effect of recurrent mitral regurgitation following degenerative mitral valve repair: Long-term analysis of competing outcomes. J. Am. Coll. Cardiol. 2016, 67, 488-498. [CrossRef] [PubMed]

22. Gelsomino, S.; Lorusso, R.; Caciolli, S.; Capecchi, I.; Rostagno, C.; Chioccioli, M.; De Cicco, G.; Bille, G.; Stefano, P.; Gensini, G.F. Insights on left ventricular and valvular mechanisms of recurrent ischemic mitral regurgitation after restrictive annuloplasty and coronary artery bypass grafting. J. Thorac. Cardiovasc. Surg. 2008, 136, 507-518. [CrossRef]

23. Hung, J.; Papakostas, L.; Tahta, S.A.; Hardy, B.G.; Bollen, B.A.; Duran, C.M.; Levine, R.A. Mechanism of recurrent ischemic mitral regurgitation after annuloplasty: Continued lv remodeling as a moving target. Circulation 2004, 110, 85-90. [CrossRef]

24. Kron, I.L.; Hung, J.; Overbey, J.R.; Bouchard, D.; Gelijns, A.C.; Moskowitz, A.J.; Voisine, P.; O'Gara, P.T.; Argenziano, M.; Michler, R.E.; et al. Predicting recurrent mitral regurgitation after mitral valve repair for severe ischemic mitral regurgitation. J. Thorac. Cardiovasc. Surg. 2015, 149, 752-761. [CrossRef]

25. Acker, M.A.; Parides, M.K.; Perrault, L.P.; Moskowitz, A.J.; Gelijns, A.C.; Voisine, P.; Smith, P.K.; Hung, J.W.; Blackstone, E.H.; Puskas, J.D.; et al. Mitral-valve repair versus replacement for severe ischemic mitral regurgitation. N. Engl. J. Med. 2014, 370, 23-32. [CrossRef] 
26. McGee, E.C.; Gillinov, A.M.; Blackstone, E.H.; Rajeswaran, J.; Cohen, G.; Najam, F.; Shiota, T.; Sabik, J.F.; Lytle, B.W.; McCarthy, P.M.; et al. Recurrent mitral regurgitation after annuloplasty for functional ischemic mitral regurgitation. J. Thorac. Cardiovasc. Surg. 2004, 128, 916-924. [CrossRef] [PubMed]

27. Roshanali, F.; Mandegar, M.H.; Yousefnia, M.A.; Rayatzadeh, H.; Alaeddini, F. A prospective study of predicting factors in ischemic mitral regurgitation recurrence after ring annuloplasty. Ann. Thorac. Surg. 2007, 84, 745-749. [CrossRef] [PubMed]

28. Goldstein, D.; Moskowitz, A.J.; Gelijns, A.C.; Ailawadi, G.; Parides, M.K.; Perrault, L.P.; Hung, J.W.; Voisine, P.; Dagenais, F.; Gillinov, A.M.; et al. Two-year outcomes of surgical treatment of severe ischemic mitral regurgitation. N. Engl. J. Med. 2016, 374, 344-353. [CrossRef]

29. Kron, I.L.; Green, G.R.; Cope, J.T. Surgical relocation of the posterior papillary muscle in chronic ischemic mitral regurgitation. Ann. Thorac. Surg. 2002, 74, 600-601. [CrossRef]

30. Harmel, E.K.; Reichenspurner, H.; Girdauskas, E. Subannular reconstruction in secondary mitral regurgitation: A meta-analysis. Heart 2018, 104, 1783-1790. [CrossRef] [PubMed]

31. Nappi, F.; Spadaccio, C.; Nenna, A.; Lusini, M.; Fraldi, M.; Acar, C.; Chello, M. Is subvalvular repair worthwhile in severe ischemic mitral regurgitation? Subanalysis of the papillary muscle approximation trial. J. Thorac. Cardiovasc. Surg. 2017, 153, 286-295. [CrossRef] [PubMed]

32. Misumi, Y.; Masai, T.; Toda, K.; Nakamura, T.; Miyagawa, S.; Yoshikawa, Y.; Fukushima, S.; Saito, S.; Domae, K.; Kainuma, S.; et al. Restrictive mitral annuloplasty with or without papillary muscle approximation for functional mitral regurgitation. J. Heart Valve Dis. 2017, 26, 447-455. [PubMed]

(C) 2019 by the authors. Licensee MDPI, Basel, Switzerland. This article is an open access article distributed under the terms and conditions of the Creative Commons Attribution (CC BY) license (http://creativecommons.org/licenses/by/4.0/). 